\title{
Correction to: Lymphocyte-to-monocyte ratio and risk of hemorrhagic transformation in patients with acute ischemic stroke
}

\author{
Quhong Song ${ }^{1} \cdot$ Ruosu Pan ${ }^{2} \cdot$ Yuxi Jin ${ }^{2} \cdot$ Yanan Wang ${ }^{1} \cdot$ Yajun Cheng ${ }^{1} \cdot$ Junfeng Liu ${ }^{1} \cdot$ Bo Wu $^{1} \cdot$ Ming Liu $^{1}$ \\ Published online: 2 November 2020 \\ (C) Fondazione Società Italiana di Neurologia 2020
}

\section{Correction to: Neurological Sciences (2020) 41:2511-2520 https://doi.org/10.1007/s10072-020-04355-Z}

We acknowledge that the published works $[1,2]$ were conducted using data from the Chengdu stroke registry database. We would like to further clarify the relationship between these manuscripts.

Song Q et al. [1] aimed to explore the association between lymphocyte-to-monocyte ratio (LMR) and overall hemorrhagic transformation (HT) and parenchymal hematoma (PH) during hospitalization in patients with acute ischemic stroke. They enrolled patients admitted to hospital within 7 days after symptom onset between January 2016 and October 2017, and the outcomes they focused were the occurrence of overall HT and $\mathrm{PH}$ during hospitalization.

However, the purpose of Wang Y et al. [2] was to investigate the relationship between monocyte to high-density lipoprotein ratio (MHR) and HT and symptomatic HT within 7 days after stroke onset. They included patients who were admitted to hospital within $24 \mathrm{~h}$ of stroke onset between January 2016 and September 2018, and the outcomes they concerned were HT and symptomatic HT within 7 days after stroke onset.

The online version of the original article can be found at https://doi.org/ 10.1007/s10072-020-04355-Z

Bo Wu

dragonwb@126.com

Ming Liu

wyplmh@hotmail.com

1 Department of Neurology, West China Hospital, Sichuan University, No.37 Guo Xue Xiang, Chengdu 610041, Sichuan Province, China

2 West China School of Medicine, Sichuan University, No.17, Section 3, People's South Road, Chengdu 610041, Sichuan Province, China
We would like to clarify that the two studies differ in terms of the purpose, inclusion criteria of participants, and outcome measures. We apologize for any inconvenience caused.

\section{References}

1. Song Q, Pan R, Jin Y, Wang Y, Cheng Y, Liu J, Wu B, Liu M. Lymphocyte-to-monocyte ratio and risk of hemorrhagic transformation in patients with acute ischemic stroke. Neurol Sci 41, 25112520 (2020). https://doi.org/10.1007/s10072-020-04355-z

2. Wang Y, Cheng Y, Song Q, et al. The association between monocyte to high-density lipoprotein ratio and hemorrhagic transformation in patients with acute ischemic stroke. Aging (Albany NY). 2020; 12(3):2498-2506. https://doi.org/10.18632/aging.102757

Publisher's note Springer Nature remains neutral with regard to jurisdictional claims in published maps and institutional affiliations. 